\title{
Insights into the catalytic properties of bamboo vacuolar invertase through mutational analysis of active site residues
}

\author{
Tai-Hung Chen ${ }^{1}$, Yu-Chiao Huang ${ }^{1}$, Chii-Shen Yang, Chien-Chih Yang, Ai-Yu Wang *, Hsien-Yi Sung * \\ Institute of Microbiology and Biochemistry and Department of Biochemical Science and Technology, National Taiwan University, No. 1, Sec. 4, Roosevelt Road, Taipei 106, Taiwan
}

\section{A R T I C L E I N F O}

\section{Article history:}

Received 9 June 2008

Received in revised form 27 September

2008

Available online 17 November 2008

\section{Keywords:}

Bambusa oldhamii

Poaceae

Bamboo

Homology modeling

Site-directed mutagenesis

Vacuolar invertase

\section{Introduction}

Sucrose is a principal product of photosynthesis, a major transport form of carbohydrates, and an important source of carbon and energy in higher plants. Utilization of sucrose for either growth or maintenance of cell activities depends on the breakdown of its glycosidic bond. Invertase (EC 3.2.1.26), which catalyzes the hydrolysis of sucrose to glucose and fructose, and sucrose synthase (EC 2.4.1.13), which converts sucrose and UDP into fructose and UDP-glucose, are the enzymes responsible for sucrose cleavage in plants. Both enzymes are crucial for plant development, growth and carbon partitioning (Sturm and Tang, 1999; Koch, 2004).

Plants possess a group of invertase isozymes that have been categorized as acid and neutral/alkaline invertases based on their $\mathrm{pH}$ optima (Tymowska-Lalanne and Kreis, 1998; Sturm, 1999; Roitsch and Gonzalez, 2004). The acid invertases are either vacuolar or cellwall-associated enzymes, while the neutral/alkaline invertases are located in the cytoplasm (Tymowska-Lalanne and Kreis, 1998; Sturm, 1999), mitochondria or plastids (Murayama and Handa, 2007). The biochemical properties of the two types of acid invertases are similar, but differ from those of neutral/alkaline invertases.

\footnotetext{
* Corresponding authors. Fax: +886223634729 (H.-Y. Sung); +886223660434 (A.-Y. Wang).

E-mail addresses: aywang@ntu.edu.tw (A.-Y. Wang), sunghy@ntu.edu.tw (H.-Y. Sung).

1 Equal contribution to this paper.
}

For example, both vacuolar and cell-wall-associated invertases are glycoproteins, but the neutral/alkaline invertases are not glycosylated. Heavy metal ions such $\mathrm{as}^{2+}$ and $\mathrm{Ag}^{+}$inhibit the activities of acid invertases but not neutral/alkaline invertases. Additionally, both types of acid invertases are $\beta$-fructofuranosidases, but neutral/alkaline invertases are not (Sturm, 1999).

In addition to their differing biochemical properties, the sequences of acid invertases show a low level of homology with neutral/alkaline invertases. Instead, acid invertases are highly homologous to fructan-synthesizing fructosyltransferases and fructan-degrading exohydrolases/fructosidases. They share several conserved regions such as the NDPNG motif, RDP motif and EC motif (Vijn and Smeekens, 1999; Ritsema and Smeekens, 2003). The importance of the conserved amino acid residues in these motifs have been proposed by a number of mutational and crystallization studies including yeast and bacterial invertases (Reddy and Maley, 1990, 1996; Alberto et al., 2004), bacterial and plant fructandegrading hydrolases (Nagem et al., 2004; Verhaest et al., 2005), plant fructan-synthesizing fructosyltransferases (Ritsema et al., 2005; Altenbach et al., 2005), and plant cell-wall-associated invertases (Goetz and Roitsch, 2000; Verhaest et al., 2006; Le Roy et al., 2007; Matrai et al., 2008; Lammens et al., 2008). However, such studies have not been performed with plant vacuolar invertases. In this paper, we report the construction of a theoretical structure of bamboo vacuolar invertase by homology modeling and changes of conserved amino acid residues by site-directed mutagenesis. The effect of each mutation on the enzymatic activity was 
characterized by expression and purification of the recombinant vacuolar invertases in yeast Pichia pastoris.

\section{Results}

\subsection{Sequence alignment and homology modeling}

Plant vacuolar invertases belong to the glycoside hydrolase family 32 (GH32) in the carbohydrate-active enzymes database (http://www.cazy.org). Fig. 1 shows the multiple sequence alignment of bamboo vacuolar invertase Boßfruct 3 with other GH32 enzymes whose crystal structures have been resolved (Alberto et al., 2004; Nagem et al., 2004; Verhaest et al., 2005, 2006). As expected, several conserved regions can be clearly noted. In order to obtain a reasonable theoretical structure of Boßfruct3, protein homology modeling was performed by using the cell-wall invertase AtcwINV1 from Arabidopsis thaliana (PDB id: 2AC1, Verhaest et al., 2006) as a template. The modeling procedure was only applied to residues Q118-N631 of Boßfruct3. The leader sequence and both the N-terminus and C-terminus of the mature protein were omitted for better accuracy. The primary model was further structurally aligned with Arabidopsis AtcwINV1 D239A mutant in complex with sucrose (PDB id: 2QQU, Lammens et al., 2008) to predict the theoretical position of sucrose when binding Boßfruct3. As shown in Figs. 2A and B, the overall structure of Boßfruct3 (residues Q118-N631) with substrate is similar to that observed for GH32 enzymes, with the $\mathrm{N}$-terminus composed of a five-bladed $\beta$-propeller module while a $\beta$-sandwich structure can be observed in the C-terminus. The three major conserved motifs, namely NDPNG, RDP and EC, are located in the active site of the enzyme (Fig. 2C).

\subsection{Mutagenic replacement and expression of recombinant mutant proteins}

To assess the role of the conserved amino acid residues in or around the active site of Boßfruct3, site-directed mutagenesis

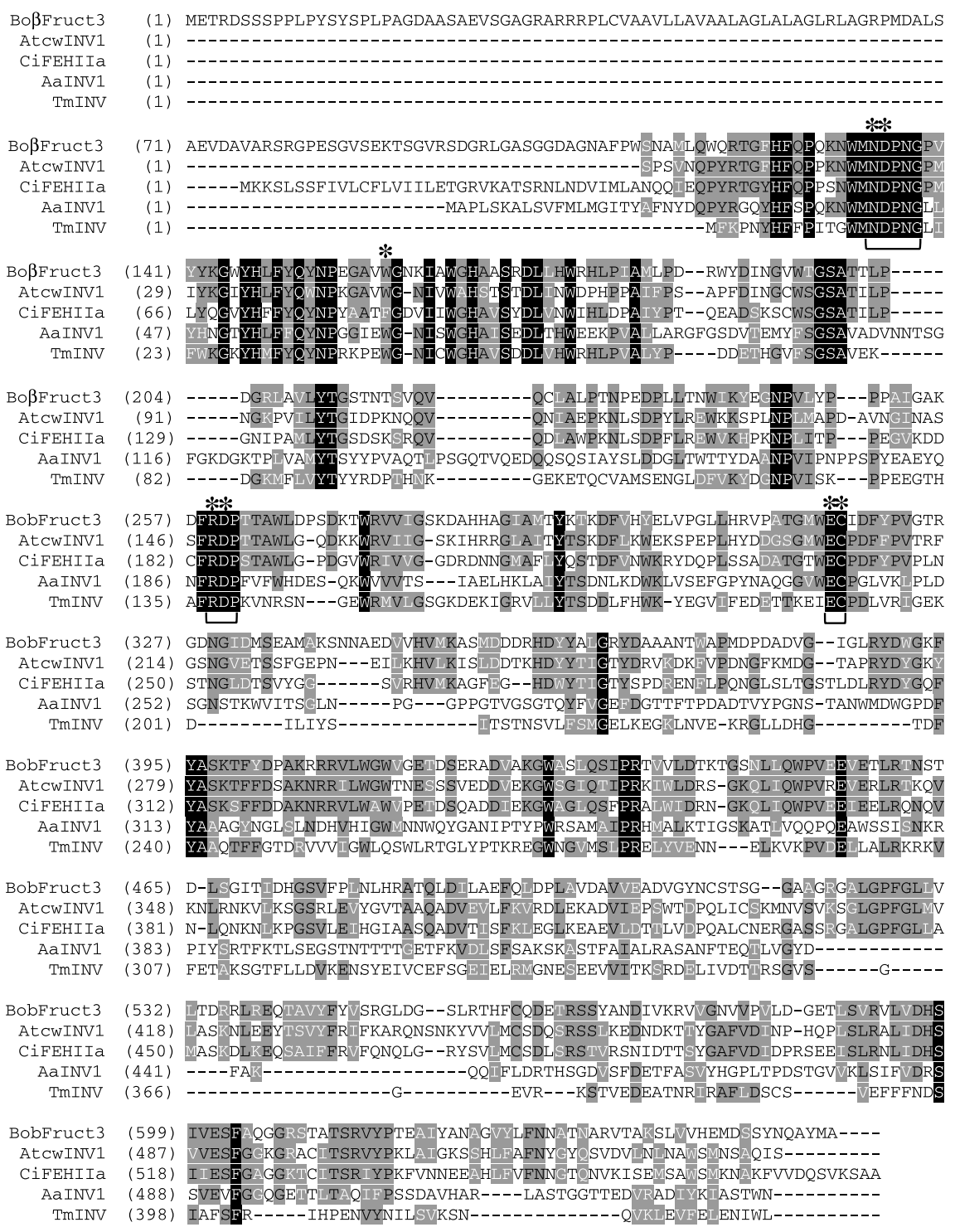

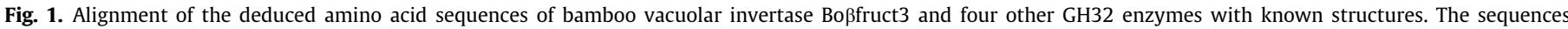

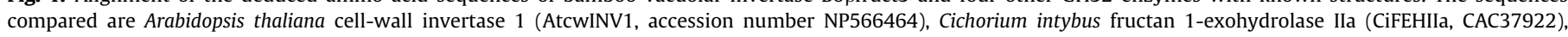

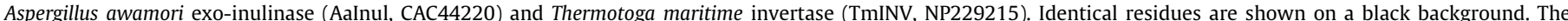

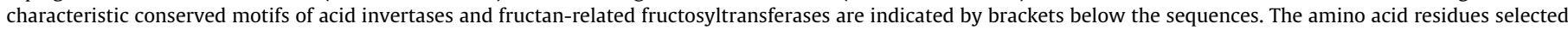
for site-directed mutagenesis are denoted by asterisks. 
was performed on Asp135, Trp159, Arg259, Asp260, Glu316 and Cys317. The plasmids containing either the mutated or wild-type Boßfruct3 cDNA were transformed into Pichia pastoris for expression of the recombinant proteins in a secreted extracellular form. After induction by methanol for $24 \mathrm{~h}$, His-tagged recombinant proteins were detected in the growth medium of each transformed $P$. pastoris strain by western analysis using an anti-(His) ${ }_{6}$ antibody (data not shown). Expression levels for different mutants varied, but each was obtained in soluble form. The wild-type enzyme and the mutants W159F, W159L, E316Q and C317A possessed different levels of acid invertase activity (data not shown). However, no invertase activity was observed either for the mutant E316A or for mutants with changes at Asp135, Arg259, or Asp260.

\subsection{Purification and characterization of the recombinant invertases}

To avoid the effect of differential protein expression by various strains on the observed activities of crude enzyme preparations, the recombinant wild-type and mutant invertases were all purified from the growth media of methanol-induced cultures using
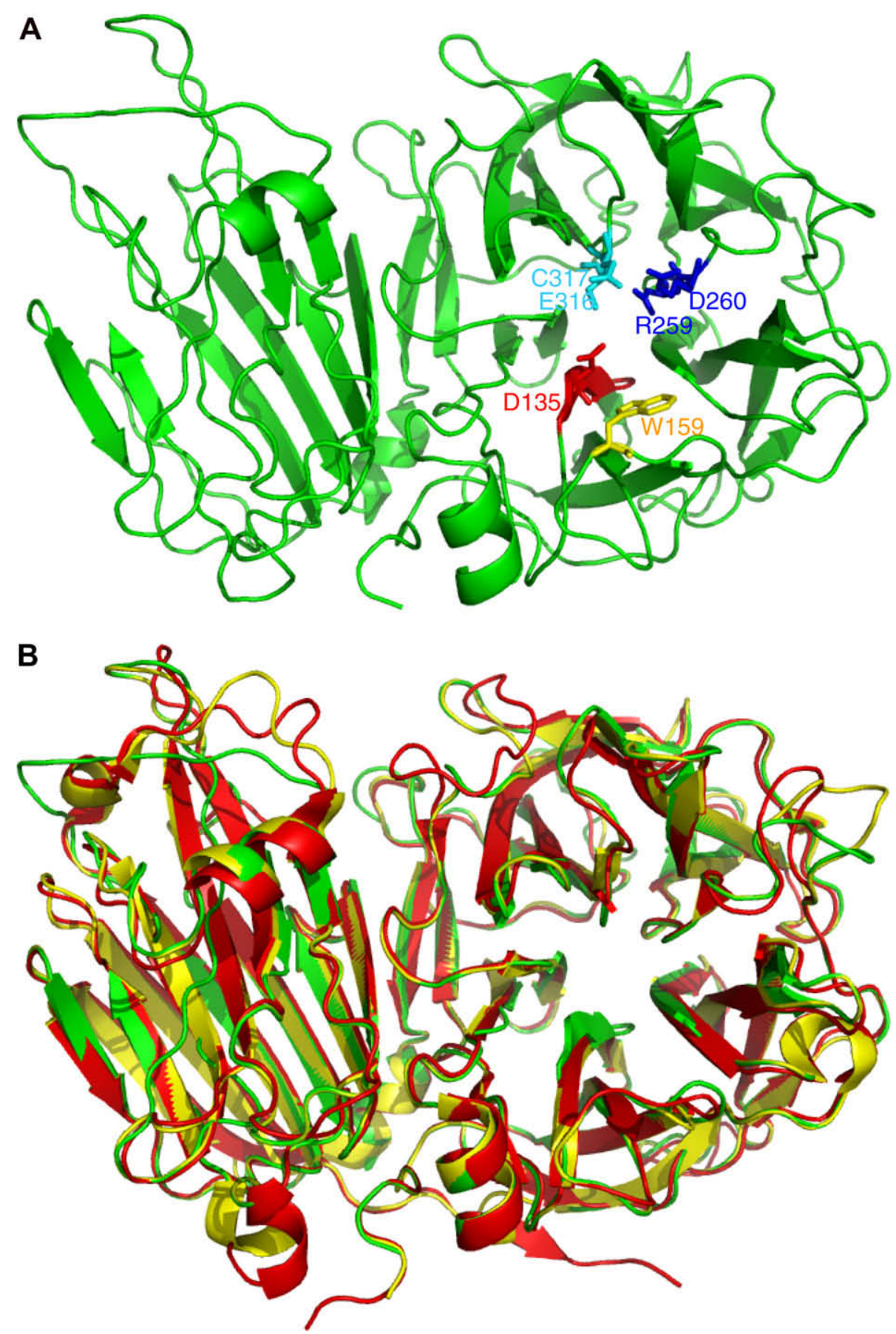

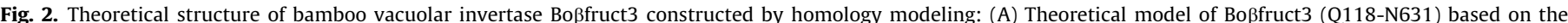

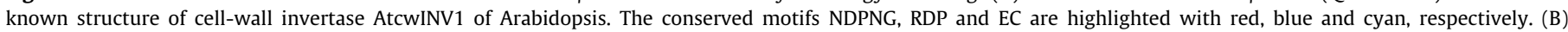

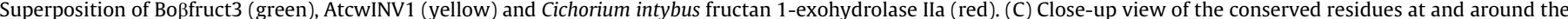

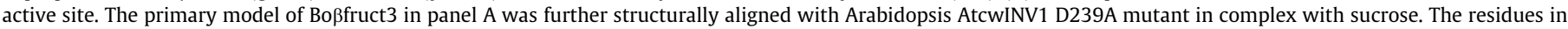
Boßfruct3, wild-type AtcwINV1 and AtcwINV1 D239A mutant are shown in green, yellow and red, respectively. 


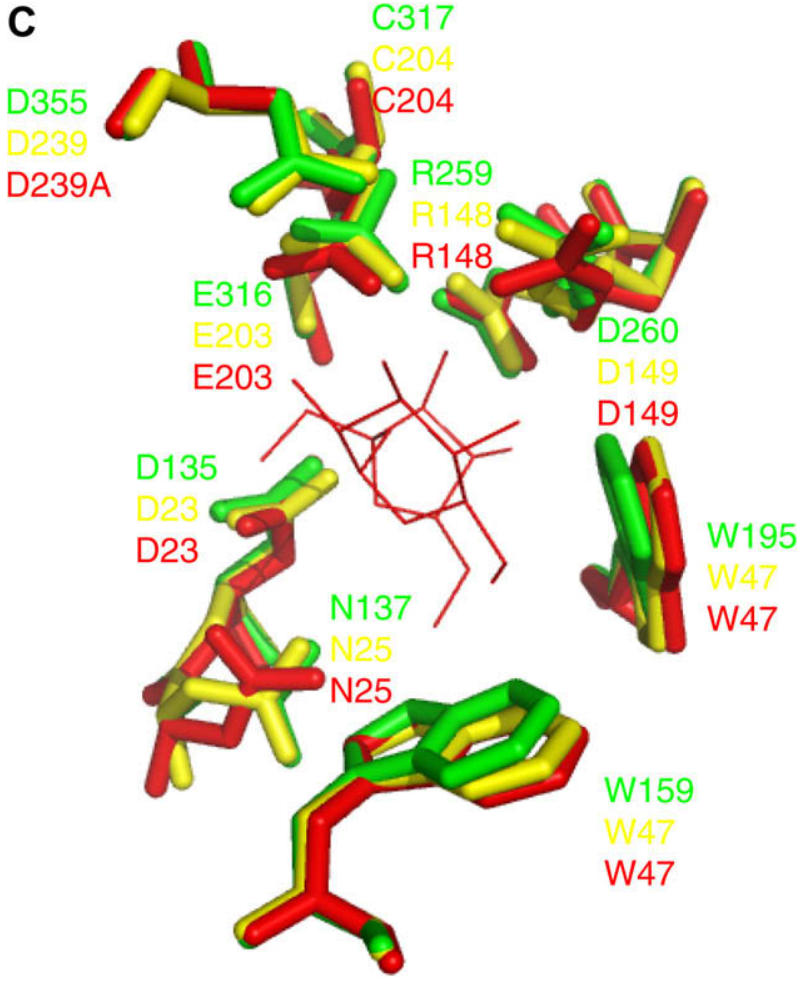

Fig. 2 (continued)

ammonium sulfate fractionation and cobalt-based IMAC (Fig. 3). The chromatograms of cobalt-based IMAC for the wild-type and mutant enzymes were similar (data not shown). The specific activities of the purified enzymes are shown in Table 1. As observed in the crude preparations, mutagenesis at Asp135 (in the NDPNG motif), Arg259 and Asp260 (both in the RDP motif) or replacement of Glu316 (in the EC motif) with alanine generated inactive enzyme, and only mutants W159F, W159L, E316Q and C317A possessed invertase activity. The mutants W159L and E316Q retained $11.7 \%$ and $67.3 \%$ of wild-type activity, respectively, while the specific activities of W159F and C317A were 4.7-fold and 2.5-fold, respectively, of that of the wild-type enzymes.

The four mutants possessing invertase activity exhibited the same $\mathrm{pH}$ optimum ( $\mathrm{pH}$ 5.0) and substrate specificity as the wildtype enzyme did. They all hydrolyzed sucrose and raffinose but could not use cellobiose, maltose, lactose and inulin as substrates. However, the relative rates of hydrolysis of raffinose by the mutants were all lower than that of the wild-type enzyme. The activ-
Table 1

Specific activities of the purified wild-type and mutant invertases.

\begin{tabular}{ll}
\hline Enzyme & Specific activity $^{\text {a }}$ (nkatal/mg) \\
\hline Wild type & 109.7 \\
D135N & 0 \\
D135E & 0 \\
W159F & 512.3 \\
W159L & 12.8 \\
R259K & 0 \\
R259L & 0 \\
D260N & 0 \\
D260E & 0 \\
E316Q & 73.9 \\
E316A & 0 \\
C317A & 271.7 \\
\hline
\end{tabular}

a Sucrose was used as the substrate to determine the activity.

Table 2

Kinetic parameters for the wild-type and mutant invertases.

\begin{tabular}{lccc}
\hline Enzyme & $K_{\mathrm{m}}(\mathrm{mM})$ & $k_{\text {cat }}\left(\mathrm{s}^{-1}\right)$ & $k_{\text {cat }} / K_{\mathrm{m}}\left(\mathrm{mM}^{-1} \mathrm{~s}^{-1}\right)$ \\
\hline Wild type & 53.68 & 501.7 & 9.35 \\
W159F & 169.77 & 2342.2 & 13.80 \\
W159L & 213.58 & 57.86 & 0.27 \\
E316Q & 142.56 & 338.41 & 2.37 \\
C317A & 140.66 & 1242.6 & 8.83 \\
\hline
\end{tabular}

ities toward raffinose were $41.0 \%, 33.2 \%, 24.3 \%, 15.5 \%$ and $20.7 \%$ of sucrose for wild-type enzyme, mutant W159F, W159L, E316Q and C317A, respectively. The effects of mutation on the $K_{\mathrm{m}}$ value for sucrose and the turnover number $\left(k_{\text {cat }}\right)$ of the enzyme were also determined (Table 2). The apparent $K_{\mathrm{m}}$ values of the four mutants possessing invertase activity were all higher than that of the wildtype enzyme. The mutants W159L and E316Q exhibited lower $k_{\text {cat }}$ values than the wild-type enzyme, but an increase in $k_{\text {cat }}$ value was observed for mutants $\mathrm{W} 159 \mathrm{~F}$ and $\mathrm{C} 317 \mathrm{~A}$. The $k_{\text {cat }} / K_{\mathrm{m}}$ ratios of W159F, W159L, E316Q and C317A were 148\%, 2.9\%, 25.3\% and $94.4 \%$ of the wild-type enzyme, respectively (Table 2 ).

\section{Discussion}

Based on the stereochemical outcomes of the hydrolysis reaction, glycoside hydrolases can be classified as either inverting or retaining enzymes. The inverting enzymes act via a general acid/ base-catalyzed direct displacement mechanism which results in overall inversion of the anomeric configuration at the site of cleavage. The retaining enzymes operate through a double-displace-
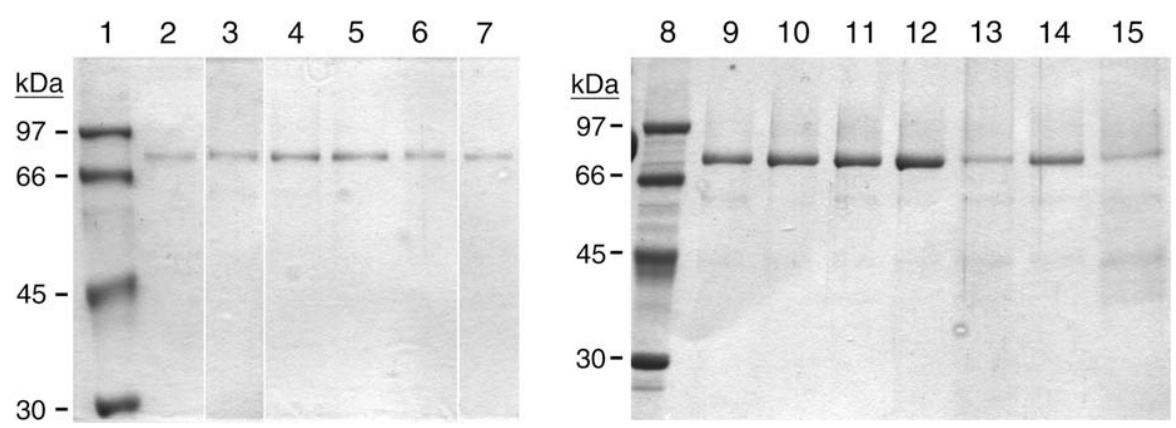

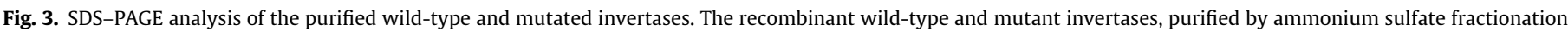

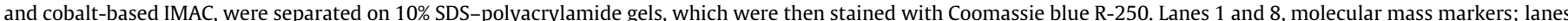

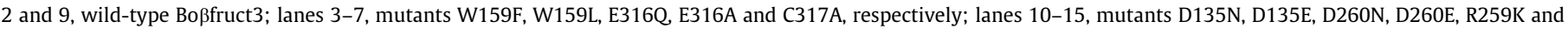
R259L, respectively. 
ment mechanism with a net retention of the anomeric configuration. The retaining mechanism involves two active site residues acting as a nucleophile and an acid/base catalyst. Attack of the anomeric center by the nucleophile results in the formation of a covalent glycosyl-enzyme intermediate, which is subsequently hydrolyzed in a general acid/base-catalyzed manner (Sinnott, 1990; Davies and Henrissat, 1995; White and Rose, 1997). Acid invertases are retaining enzymes. By affinity labeling and site-directed mutagenesis, Reddy and Maley $(1990,1996)$ first proposed that the nucleophile and the acid/base catalyst in the active site of yeast invertase were the Asp residue in the NDPNG motif and the Glu residue in the EC motif, respectively. The proposed catalytic mechanism is as follows: the Glu residue protonates the glycosidic oxygen of sucrose and the nucleophile Asp attacks C-2 of the fructose moiety, forming a fructosyl-enzyme intermediate and releasing glucose. Subsequently, the Glu abstracts a proton from water, which enables the hydroxyl group to displace fructose and restore the original active center (Reddy and Maley, 1996). The NDPNG and EC motifs are highly conserved across invertases and fructan-related fructosyltransferases. Replacing the homologs Asp with Asn or Glu with Ala, which resulted in inactive enzymes, has also been reported for other invertase and fructosyltransferases (Goetz and Roitsch, 2000; Ozimek et al., 2004; Ritsema et al., 2005). Analyses of crystal structures confirmed that these two amino acid residues, together with the Asp residue of RDP motif, are located in the active site of invertases and fructan-metabolizing enzymes (Alberto et al., 2004; Nagem et al., 2004; Verhaest et al., 2005; Verhaest et al., 2006; Lammens et al., 2008). By homology modeling, we have shown that the theoretical structure of bamboo vacuolar invertase Boßfruct3 (residues Q118-N631) is similar to the resolved crystal structures of Arabidopsis cell-wall invertase and the other three GH32 enzymes. The homologs of the nucleophile Asp and the acid/base catalyst Glu in Boßfruct3 are Asp135 and Glu316, respectively. The critical requirement of Asp135 was supported by the results of site-directed mutagenesis. No catalytic activity was detected in mutant D135N (Table 1). Even when Asp135 was replaced with Glu, a residue with only one more $-\mathrm{CH}_{2}$ in the side-chain, the enzymatic activity was not retained (Table 1), indicating the importance of the structural distance and orientation for nucleophilic attack.

The results of mutagenesis at Glu316 also suggested its importance in the active site but its specific role remains uncertain. Replacement of Glu316 with Ala generated an inactive enzyme; however, the mutant $\mathrm{E} 316 \mathrm{Q}$ retained $67 \%$ activity of the wild-type enzyme (Table 1). In Arabidopsis AtcwINV1, Glu203 was identified as the acid/base catalyst in the active site. The mutant E203A exhibited a drastic decrease in $k_{\text {cat }}$ value (Le Roy et al., 2007) and mutant E203Q was inactive (Matrai et al., 2008; Lammens et al., 2008). The X-ray crystallographic structure of the E203Q in complex with sucrose showed that the sugar binding and the catalytic pocket arrangement is significantly altered in this mutant (Matrai et al., 2008; Lammens et al., 2008). Although the theoretical structure of Boßfruct3 (residues Q118-N631) is similar to the revolved structures of AtcwINV1, the difference in enzymatic activity between Boßfruct3 E316Q mutant and AtcwINV1 E203Q mutant suggests that the two homologous residues may not have exactly same role in the two enzymes. The reaction catalyzed by the retaining glycoside hydrolases usually involves two carboxyl groups acting as a nucleophile and an acid/base catalyst (Sinnott, 1990; Davies and Henrissat, 1995; White and Rose, 1997) but variants of the acid/base catalyst exist in some enzymes (Zechel and Withers, 2001; Burmeister et al., 1997). For example, in plant myrosinase (thioglucoside glucohydrolase), which belongs to family 1 of glycoside hydrolases and also is a retaining enzyme, the Glu residue at the usual position of the acid-base catalyst is naturally replaced by Gln. The role of this $\mathrm{Gln}$ is thought to ensure a precise positioning of a water molecule, rather than to provide general base assistance. The positioning of the water molecule is sufficient to hydrolyze the glycosyl-enzyme intermediate. Ascorbate, a cofactor for myrosinase, can substitute for the function of the catalytic base (Burmeister et al., 1997, 2000). We propose that the Glu316 in wild-type Boßfruct3 functions as an acid/base catalyst that enhances the rate of sucrose hydrolysis. When Glu316 is replaced with another amino acid residue that can provide the hydrogenbond network for positioning the water, the hydrolysis reaction still can occur, but at lower rate, in acidic condition in which protonation of the glycosidic oxygen of sucrose by an acid/base catalyst could be unnecessary. However, it requires further investigation.

In addition to the two amino acid residues that may be directly involved in catalysis in the active site, other conserved residues in or around the active site were also examined, including Trp159, Arg259, Asp260 and Cys317.

Trp159 is located between the NDPNG and RDP motifs. The corresponding residue in $T$. maritime invertase was reported to form a hydrogen-bond with the hydroxyl group of the C6 of fructose (Alberto et al., 2004). Replacing Trp159 with either Leu or Phe resulted in increases in $K_{\mathrm{m}}$ values for sucrose, confirming its role in fructose binding. Interestingly, the two mutations had opposite effects on the turnover number and specificity constant of the enzyme (Table 2). There were 8.7-fold and 34.6-fold reductions in the $k_{\text {cat }}$ and $k_{\text {cat }} / K_{\mathrm{m}}$ values of W159L, but 4.7 -fold and 1.5 -fold increases in the $k_{\text {cat }}$ and $k_{\text {cat }} / K_{\mathrm{m}}$ values of $\mathrm{W} 159 \mathrm{~F}$ as compared to the wild-type enzyme. The results indicated that the aromatic side-chain of the residue in this position was important for efficient catalysis. The increase in the $k_{\text {cat }}$ value of W159F can be explained by assuming that the interaction between Phe and fructose is weaker than that between Trp and fructose. Therefore, once the enzyme is saturated with sucrose and the catalytic reaction has occurred, the second product, fructose, can be released more readily from the active site of $\mathrm{W} 159 \mathrm{~F}$ than from that of the wild-type enzyme.

Both Arg259 and Asp260 are part of the RDP motif. The Asp residue is conserved and occurs in the active site of invertases and fructan-metabolizing enzymes. However, it was suggested that this residue does not have a direct function during catalysis but may affect the nucleophilicity of the nucleophile Asp in the NDPNG motif (Nagem et al., 2004; Verhaest et al., 2006). Alberto et al (2004) proposed that the Arg and Asp in the RDP motif (Arg137 and Asp138 in T. maritime invertase) play crucial roles in substrate binding and recognition since the former is hydrogen-bonded to the glucose $\mathrm{O} 4$ and the latter forms hydrogen-bonds to $\mathrm{O} 3$ and O4 of the fructose unit. In AtcwINV1, the Asp149 of the RDP motif was reported to have a role in stabilization of the fructose ring; Arg148, together with W82, D239 and K242, have an influence on the orientation of glucose (Lammens et al., 2008). In this study, the Arg259 was changed to Lys or Leu and Asp260 was replaced with Asn or Glu. The mutations all resulted in the complete loss of enzymatic activity, in spite of the retention of positive and negative charges by Lys and Glu, respectively. Since the RDP motif is connected by two flexible coils and turn structures, mutations at Arg259 or Asp260 may cause conformational disturbances and a less stable local structure, which consequently lead to changes in substrate binding orientation and prevention of catalysis.

Cys317 and the preceding Glu316 (the acid/base catalyst) reside in the EC motif. The cysteine in the EC motif is thought to play a role in transition state stabilization and/or the catalytic residue microenvironment in T. maritime invertase, since it forms hydrogen-bonds to the two Asp residues in the active site (Alberto et al., 2004). However, replacement of this conserved cysteine with other residues has different effects on the activity of invertases from different species. In yeast, the mutant C205A exhibited 
decreased affinity for sucrose and $k_{\text {cat }}$, and a 6 -fold reduction in the $k_{\text {cat }} / K_{\mathrm{m}}$ value (Reddy and Maley, 1996), while in C. rubrum, the mutant C237S was inactive (Goetz and Roitsch, 2000). In this study, the mutant C317A of Boßfruct3 was found to exhibit higher $K_{\mathrm{m}}$ and $k_{\text {cat }}$ values than the wild-type enzyme, but the specificity constant was not significantly changed. The results indicate that the function of this residue in transition state stabilization and/or the catalytic residue microenvironment was not significant, and it may instead have a role in substrate binding.

Recent studies on the AtcwINV1 mutants showed that next to the highly conserved residues of the NDPNG, EC and RDP motif, Trp82, Asp239 and Lys242 are additional key residues in stabilization of the substrate molecule (Le Roy et al., 2007; Matrai et al., 2008; Lammens et al., 2008). The Asp239 can interact directly with the glucose moiety of sucrose. Substitution of Asp239 with alanine alters substrate specificity of AtcwINV1 into a 1-kestose (Le Roy et al., 2007). In Boßfruct3, the Trp82, Asp239 and Lys242 homologs are Trp159, Asp355 and Arg358, respectively. Whether the functions of these residues are conserved in different invertases or not will be investigated in the future.

\section{Conclusions}

The results of this study demonstrate that the conserved residues in or around the active site of bamboo vacuolar invertase Boßfruct3 have individual functions in catalyzing sucrose hydrolysis. Our results also suggest that, as long as the conformation of the active site is properly maintained, decreasing the affinity of the enzyme for substrate by mutagenesis at Trp159 and Cys317 can increase the turnover number of the enzyme, probably by facilitating the release of reaction products from the enzyme. Although this finding requires further investigation, it suggests a possible way to engineer this enzyme for application.

\section{Experimental}

\subsection{General experimental procedures}

The QuickChange site-directed mutagenesis kit was from Stratagene (La Jolla, CA). The cobalt-based immobilized metal affinity chromatography (IMAC) resin was from BD Biosciences Clontech (Palo Alto, CA). Yeast extract, peptone and yeast nitrogen base were obtained from Becton, Dickinson and Company (Sparks, MD). Other chemicals were from Sigma-Aldrich (St. Louis, MO).

\subsection{Homology modeling and structure prediction}

Residues of plant vacuolar invertases Boßfruct3 from Q118N631 were submitted to the Swiss-Model server (http://swissmodel.expasy.org) to perform sequence analysis, and a protein from $A$. thaliana (PDB id: 2 AC1) showing $47 \%$ sequence identity was thus determined as the best template for model construction. The model returned from the server was further structurally aligned with Arabidopsis AtcwINV1 D239A mutant in complex with sucrose (PDB id: 2QQU) with Pymol 0.99rc6 (DeLano Scientific, CA, USA) in order to predict the theoretical position of sucrose when binding with Boßfruct3. A final model was proposed after performing energy minimization with DeepView 3.7 (Guex and Peitsch, 1997).

\subsection{Plasmid and site-directed mutagenesis}

Plasmid pBoIT3, which was constructed by insertion of the coding region of Boßfruct3 cDNA into the EcoRI/Xbal site of the Pichia expression vector pPICZ $\alpha \mathrm{B}$ (Hsieh et al., 2006), was used for expression of the wild-type recombinant invertase in yeast, and
Table 3

Primers used for the mutagenesis of Bopfruct3 cDNA.

\begin{tabular}{ll}
\hline Mutation & Nucleotide sequence \\
\hline D135N & S: 5'-CAGAAGAACTGGATGAACAACCCTAACGGGCCTGTG-3' \\
& As: 5'-CCCGTTAGGGTTGTTCATCCAGTTCTTCTGAGGCTG-3 \\
D135E & S: 5'-CAGAAGAACTGGATGAACGAGCCTAACGGGCCTGTG-3' \\
& As: 5'-CCCGTTAGGCTCGTTCATCCAGTTCTTCTGAGGCTG-3' \\
W159F & S: 5'-GAGGGCGCGGTGTTCGGCAACAAGATCGCCTGGG-3' \\
& As: 5'-CTTGTTGCCGAACACCGCGCCCTCCGGGTTGAC-3' \\
W159L & S: 5'-GGCGCGGTGCTGGGCAACAAGATCGCCTGGG-3' \\
& As: 5'-GATCTTGTTGCCCAGCACCGCGCCCTCCGG-3' \\
R259K & S: 5'-GCCAAGGACTTCAAGGACCCCACCACCGCCTGG-3' \\
& As: 5'-GGTGGGGTCCTTGAAGTCCTTGGCGCCATGGC-3' \\
R259L & S: 5'-GCCAAGGACTTCCTGGACCCCACCACCGCCTGG-3' \\
& As: 5'-GGTGGGGTCCAGGAAGTCCTTGGCGCCGATGGC-3' \\
D260N & S: 5'-AAGGACTTCCGCAACCCCACCACCGCCTGGC-3' \\
& As: 5'-GGTGGTGGGGTTGCGGAAGTCCTTGGCGCCG-3' \\
D260E & S: 5'-AAGGACTTCCGCGAGCCCACCACCGCCTGG-3' \\
& As: 5'-GGTGGTGGGCTCGCGGAAGTCCTTGGCGCC-3' \\
E316Q & S: 5'-GCCACCGGCATGTGGCAGTGCATCGACTTCTACCCC-3' \\
& As: 5'-GAAGTCGATGCACTGCCACATGCCGGTGGCCGGGAC-3' \\
E316A & S: 5'-GCCACCGGCATGTGGGCCTGCATCGACTTCTACCCC-3' \\
& As: 5'-GAAGTCGATGCAGGCCCACATGCCGGTGGCCGGGAC-3' \\
C317A & S: 5'-GGCATGTGGGAGGCCATCGACTTCTACCCC-3' \\
& As: 5'-GAAGTCGATGGCCTCCCACATGCCGGTGGC-3'
\end{tabular}

as a template DNA for the generation of mutated plasmids. Site-directed mutagenesis was carried out using the QuickChange site-directed mutagenesis kit and mutagenic primer pairs (Table 3 ).

\subsection{Expression and purification of the wild-type and mutated invertases in yeast}

Pichia pastoris strain X-33 was transformed with plasmid pBoIT3 or mutated plasmids by electroporation. The transformed cells were grown in buffered glycerol-complex medium $[0.1 \mathrm{M}$ potassium phosphate, $\mathrm{pH} 6.0,1 \%(\mathrm{w} / \mathrm{v})$ yeast extract, $2 \%(\mathrm{w} / \mathrm{v})$ peptone, $1.34 \%(\mathrm{w} / \mathrm{v})$ yeast nitrogen base $(\mathrm{YNB}), 4 \times 10^{-5} \%(\mathrm{w} / \mathrm{v})$ biotin and $1 \%(\mathrm{v} / \mathrm{v})$ glycerol] at $30^{\circ} \mathrm{C}$ until the $\mathrm{A}_{600}$ value reached 1.0. The cells were collected by centrifugation and then resuspended in the buffered $\mathrm{MeOH}$-complex medium [0.1 M potassium phosphate, $\mathrm{pH}$ $6.0,1 \%(\mathrm{w} / \mathrm{v})$ yeast extract, $2 \%(\mathrm{w} / \mathrm{v})$ peptone, $1.34 \%(\mathrm{w} / \mathrm{v}) \mathrm{YNB}$, $4 \times 10^{-5} \%(\mathrm{w} / \mathrm{v})$ biotin and $\left.0.5 \%(\mathrm{v} / \mathrm{v}) \mathrm{MeOH}\right]$ containing $1 \%$ casamino acid, and were grown at $30^{\circ} \mathrm{C}$ for $24 \mathrm{~h}$.

For purification of the recombinant invertases secreted in the medium, the methanol-induced cultures were centrifuged at $6000 \mathrm{~g}$ for $30 \mathrm{~min}$ to remove cells. The proteins in the supernatants were precipitated by $80 \%$ saturation of ammonium sulfate followed by centrifugation. The precipitates were then dissolved in PB-7.0 (50 mM sodium phosphate, pH 7.0) and dialyzed against $\mathrm{PB}-7.0$ containing $0.3 \mathrm{M} \mathrm{NaCl}$. The resultant enzyme solution was mixed with cobalt-based IMAC resin and incubated for $1 \mathrm{~h}$ at $4{ }^{\circ} \mathrm{C}$. The enzyme-resin mixture was then packed into a column, washed with PB-7.0 containing $0.3 \mathrm{M} \mathrm{NaCl}$ and $10 \mathrm{mM}$ imidazole, and eluted with $\mathrm{PB}-7.0$ containing $0.3 \mathrm{M} \mathrm{NaCl}$ and $150 \mathrm{mM}$ imidazole. Proteins in each fraction were analyzed by $12.5 \%$ SDS-PAGE. After electrophoresis, the proteins on the gels were stained with Coomassie Blue R-250 or were transferred onto PVDF membranes for immunodetection using an anti-(His) 6 antibody. Fractions containing the recombinant invertase proteins were collected.

\subsection{Acidic invertase assay and enzyme kinetics}

The reaction mixture contained $0.1 \mathrm{M}$ sodium acetate, $\mathrm{pH} 5.0$, $0.1 \mathrm{M}$ sucrose and an appropriate amount of enzyme. After incubation at $37^{\circ} \mathrm{C}$, the amount of reducing sugars (glucose and fructose) produced was measured by the method of Somogyi-Nelson (Nelson, 1944). For routine assay of invertase activity during puri- 
fication of the enzyme, the incubation time was $20 \mathrm{~m}$. For determination of kinetic parameters, the reactions were performed for various time periods to obtain initial velocities. The sucrose concentrations used in kinetic analysis were $0,20,40,60,80$, $100,150,200$ and $300 \mathrm{mM}$. One unit of activity was defined as the amount of enzyme that catalyzed the formation of $1 \mu \mathrm{mol}$ of reducing sugar from sucrose in $1 \mathrm{~h}$ at $37^{\circ} \mathrm{C}$. The kinetic constants were determined from the Eadie-Hofstee plot using the program Enzyme Kinetics!Pro (ChemSW Software, CA). The $k_{\text {cat }}$ values were calculated on the basis of a molecular mass of 76,200 Da, as determined by gel filtration chromatography.

\section{Acknowledgements}

This work was supported by grants from the National Science Council, the Republic of China (Taiwan).

\section{References}

Alberto, F., Bignon, C., Sulzenbacher, G., Henrissat, B., Czjzek, M., 2004. The threedimensional structure of invertase (beta-fructosidase) from Thermotoga maritima reveals a bimodular arrangement and an evolutionary relationship between retaining and inverting glycosidases. J. Biol. Chem. 279, 1890318910.

Altenbach, D., Nuesch, E., Ritsema, T., Boller, T., Wiemken, A., 2005. Mutational analysis of the active center of plant fructosyltransferases: festuca 1-SST and barley 6-SFT. FEBS Lett. 579, 4647-4653.

Burmeister, W.P., Cottaz, S., Driguez, H., Iori, R., Palmieri, S., Henrissat, B., 1997. The crystal structures of Sinapis alb a myrosinase and a covalent glycosyl-enzyme intermediate provide insights into the substrate recognition and active-site machinery of an S-glycosidase. Structure 5, 663-675.

Burmeister, W.P., Cottaz, S., Cottaz, S., Rollin, P., Vasella, A., Henrissat, B., 2000. High resolution X-ray crystallography shows that ascorbate is a cofactor for myrosinase and substitutes for the function of the catalytic base. J. Biol. Chem. 275, 39385-39393.

Davies, G., Henrissat, B., 1995. Structures and mechanisms of glycosyl hydrolases. Structure 3, 853-859.

Goetz, M., Roitsch, T., 2000. Identification of amino acids essential for enzymatic activity of plant invertases. J. Plant Physiol. 157, 581-585.

Guex, N., Peitsch, M.C., 1997. SWISS-MODEL and the Swiss-Pdb viewer: an environment for comparative protein modeling. Electrophoresis 18, 27142723.

Hsieh, C.W., Liu, L.K., Yeh, S.H., Chen, C.F., Lin, H.I., Sung, H.Y., Wang, A.Y., 2006 Molecular cloning and functional identification of invertase isozymes from green bamboo Bambusa oldhamii. J. Agric. Food Chem. 54, 3101-3107.

Koch, K., 2004. Sucrose metabolism: regulatory mechanisms and pivotal roles in sugar sensing and plant development. Curr. Opin. Plant Biol. 7, 235-246.

Lammens, W., Le Roy, K., Van Laere, A., Rabijns, A., Van den Ende, W., 2008. Crysta structures of Arabidopsis thaliana cell-wall invertase mutants in complex with sucrose. J. Mol. Biol. 377, 378-385.
Le Roy, K., Lammens, W., Verhaest, M., De Coninck, B., Rabijns, A., VanLaere, A., Van den Ende, W., 2007. Unraveling the difference between invertases and fructan exohydrolases: a single amino acid (Asp-239) substitution transforms Arabidopsis cell-wall invertase1 into a fructan 1-exohydrolase. Plant Physiol. $145,616-625$.

Matrai, J., Lammens, W., Jonckheer, A., Le Roy, K., Rabijns, A., Van den Ende, W., De Maeyer, M., 2008. An alternate sucrose-binding mode in the E203Q Arabidopsis invertase mutant: an X-ray crystallography and docking study. Proteins 71, 552-564.

Murayama, S., Handa, H., 2007. Genes for alkaline/neutral invertase in rice: alkaline/ neutral invertases are located in plant mitochondria and also in plastids. Planta 225, 1193-1203.

Nagem, R.A., Rojas, A.L., Golubev, A.M., Korneeva, O.S., Eneyskaya, E.V., Kulminskaya, A.A., Neustroev, K.N., Polikarpov, I., 2004. Crystal structure of exo-inulinase from Aspergillus awamori: the enzyme fold and structural determinants of substrate recognition. J. Mol. Biol. 344, 471-480.

Nelson, N., 1944. A photometric adaptation of the Somogyi method for the determination of glucose. J. Biol. Chem. 153, 375-380.

Ozimek, L.K., van Hijum, S.A., van Koningsveld, G.A., van Der Maarel, M.J., van GeelSchutten, G.H., Dijkhuizen, L., 2004. Site-directed mutagenesis study of the three catalytic residues of the fructosyltransferases of Lactobacillus reuteri 121. FEBS Lett. 560, 131-133.

Reddy, A., Maley, F., 1996. Studies on identifying the catalytic role of Glu-204 in the active-site of yeast invertase. J. Biol. Chem. 271, 13953-13957.

Reddy, V.A., Maley, F., 1990. Identification of an active-site residue in yeast invertase by affinity labeling and site-directed mutagenesis. J. Biol. Chem. 265, 10817-10820.

Ritsema, T., Smeekens, S.C., 2003. Engineering fructan metabolism in plants. J. Plant Physiol. 160, 811-820.

Ritsema, T., Verhaar, A., Vijn, I., Smeekens, S., 2005. Using natural variation to investigate the function of individual amino acids in the sucrose-binding box of fructan: fructan $6 \mathrm{G}$-fructosyltransferase $(6 \mathrm{G}-\mathrm{FFT})$ in product formation. Plant Mol. Biol. 58, 597-607.

Roitsch, T., Gonzalez, M.C., 2004. Function and regulation of plant invertases: sweet sensations. Trend Plant Sci. 9, 606-613.

Sinnott, M.L., 1990. Catalytic mechanisms of enzymic glycosyl transfer. Chem. Rev. 90, 1171-1202.

Sturm, A., 1999. Invertases. Primary structures, functions, and roles in plant development and sucrose partitioning. Plant Physiol. 121, 1-8.

Sturm, A., Tang, G.Q., 1999. The sucrose-cleaving enzymes of plants are crucial for development, growth and carbon partitioning. Trend Plant Sci. 4, 401-407.

Tymowska-Lalanne, Z., Kreis, M., 1998. Expression of the Arabidopsis thaliana invertase gene family. Planta 207, 259-265.

Verhaest, M., Ende, W.V., Roy, K.L., De Ranter, C.J., Laere, A.V., Rabijns, A., 2005. X-ray diffraction structure of a plant glycosyl hydrolase family 32 protein: fructan 1 exohydrolase IIa of Cichorium intybus. Plant J. 41, 400-411.

Verhaest, M., Lammens, W. Le Roy, K., De Coninck, B., De Ranter C.J. Van Laere, A. Van den Ende, W., Rabijns, A., 2006. X-ray diffraction structure of a cell-wall invertase from Arabidopsis thaliana. Acta Crystallogr. D: Biol. Crystallogr. 62, 1555-1563.

Vijn, I., Smeekens, S., 1999. Fructan: more than a reserve carbohydrate? Plant Physiol. 120, 351-360.

White, A., Rose, D.R., 1997. Mechanism of catalysis by retaining $\beta$-glycosyl hydrolases. Curr. Opin. Struct. Biol. 7, 645-651.

Zechel, D.L., Withers, S.G., 2001. Dissection of nucleophilic and acid-base catalysis in glycosidases. Curr. Opin. Chem. Biol. 5, 643-649. 